\title{
Cultures in Contact: Using Classroom Microcomputers for Cultural Interchange and Reinforcement ${ }^{1}$
}

Jim Cummins

This article explores a number of ways in which microcomputers may be used in classrooms, both to enhance academic skills and to provide opportunities for communication with groups of students in other cultural contexts.

With the computer as the instrument, writing is more like talking. Writers interact with the computer instrument, while the pen and the typewriter are static tools. The computer enhances the communication functions of writing not only because it interacts with the writers but also because it offers a channel for writers to communicate with one another and because it can carry out a variety of production activities. Writing on the computer means using the machine as a pencil, eraser, typewriter, printer, scissors, paste, copier, filing cabinet, memo pad, and post office. Thus, the computer is a communication channel as well as a writing tool. (Collette Daiute, Writing and Computers, 1985, p. xiv)

Many thoughtful educators have expressed concerns that the technological changes which are transforming schools throughout the world will erode the foundations of humanistic orientations to education. They fear that microcomputers, in particular, will control all forms of human learning with the result that students will no longer be encouraged to explore the complexities of human existence, the evolution of different cultures and value systems, and the literature that has expressed our struggle to understand ourselves and our history. The scenario they envisage is of the soulless machine presiding over a spiritual vacuum.

These concerns are not without foundation. Several surveys have shown that computers in North American schools are used predominantly for drill and practice activities (e.g. Becker, 1982). In other words, the computer is used as an electronic workbook to reinforce the acquisition of particular academic skills (e.g. spelling, computation, etc.). Typically, these skills involve relatively low level cognitive activities such as rote memorization or acquisition of simple rules.

We tend to view the computer as the culprit for the narrow educational uses to which it is frequently applied. However, the computer is simply a 
machine which has been programmed by people who are operating with certain implicit or explicit assumptions about teaching and learning. It is a tool whose educational uses are still being explored.

I want to make two major points in this paper. First, the question about how computers should be used in schools and whether their impact is likely to be positive or negative is not, in reality, a question about computers; it is a question about educational philosophy and about the psychology of learning and teaching. All educational software incorporates assumptions about how children learn best and about appropriate ways of teaching children. Critical examination of the underlying pedagogical model is a prerequisite for the evaluation of software and appropriate use of microcomputer hardware.

The second point I want to make is that when microcomputers are applied within an appropriate pedagogical framework, they have the potential to radically improve the quality of education children receive. Specifically, the computer has the potential to make the "global village" a reality for students by allowing them to interact directly with other students around the world. In other words, when used appropriately, the computer has enormous potential for cultural interchange and reinforcement; by interacting through writing with their peers in different parts of the world, students simultaneously explore the values and history of other cultures and, in the process, discover what is unique about their own. Enhancement of basic language and literacy skills are by-products of this interaction.

I will first examine the two alternative pedagogical models that underlie the major uses to which computers are currently being put. Then, recent developments in the teaching of writing will be reviewed as well as research on classroom uses of microcomputers. Finally, an ongoing project of the National Heritage Language Resource Unit (NHLRU) of the Ontario Institute for Studies in Education (OISE) to establish an international student computer writing network will be described and its specific implications for ESL students discussed. It will be argued that for ESL students, whose first language and cultural identity are often fragile, the cultural and linguistic reinforcement provided by computer writing networks is particularly significant. In short, the classroom microcomputer, when used appropriately, can become a potent force for promoting crosscultural understanding and the goals of humanistic education.

\section{TRANSMISSION VERSUS INTERACTIONAL MODELS OF PEDAGOGY}

The predominant use of computers for reinforcing skills and knowledge reflects an underlying educational philosophy which has been 
termed a "transmission" model of teaching (Barnes 1976; Welss 1982). The basic premise of this model is that the teacher's task is to impart knowledge or skills that $\mathrm{s} /$ he possesses to students who do not yet have these skills. This implies that the teacher initiates and controls the interaction, constantly orienting it towards the achievement of instructional objectives. For example, in first and second language programs that stress pattern repetition, the teacher presents the materials, models the language patterns, asks questions, and provides feedback to students about the correctness of their response. Both in the case of regular curriculum development and educational software development, the transmission model emphasizes analysis of academic task demands, establishment of sequential learning objectives based on this task analysis, and "direct instruction" of individual task components, proceeding from "simpler" lower level subskills to more complex integrations of these subskills.

The application of this general instructional orientation is outlined clearly in the following account of task analysis:

This process requires that concepts be broken into task components, which are then broken into skills. Finally, steps are outlined to help the student master each skill. By following this procedure, the teacher can develop a list of skills which, when mastered, will yield a successfully completed task. In turn, as several tasks are learned, concepts will be mastered.... Once the component steps of a task have been identified, the child is presented with each sequential task until a task is presented that the child can perform without error. (Plata, 1982, p. 26-27)

Task analysis is an appropriate approach to the teaching of certain kinds of knowledge and skills. However, a broader view of education would encompass much more than just the transmission of knowledge and skills. In this broader view genuine understanding is seen as involving active discovery on the part of the child rather than just consumption of pre-determined knowledge. Similarly, the development of higher levels of cognitive and literacy skills requires considerably more active and instrinsically-motivated involvement on the part of the student than is implied by the transmission model. In fact, it has been argued that a transmission model of teaching contravenes central principles of language and literacy acquisition and that a model allowing for "reciprocal interaction" among students and teachers represents a more appropriate alternative (Cummins, 1984; Wells, 1982). This model incorporates proposals about the relations between language and learning made by a variety of investigators, most notably in the Bullock Report (HMSO, 1975), and by Barnes (1976), Lindfors (1980) and Wells (1981). Its applications with respect to the promotion of literacy conform closely to psycholinguistic approaches to reading (e.g. Goodman \& Goodman, 1977; Holdaway, 
1979; Smith, 1978) and to the recent emphasis on encouraging expressive writing from the earliest grades (e.g. Chomsky, 1981; Giacobbe, 1982; Graves, 1983; Temple, Nathan, \& Burris, 1982).

A central tenet of the reciprocal interaction model is that "talking and writing are means to learning" (Bullock Report, HMSO, 1975, p. 50). Its major characteristics in comparison to a transmission model are as follows:

- genuine dialogue between student and teacher in both oral and written modalities

- guidance and facilitation rather than control of student learning by the teacher

- encouragement of student-student talk in a collaborative learning context

- encouragement of meaningful language use by students rather than correctness of surface forms

- conscious integration of language use and development with all curricular content rather than teaching language and other content as isolated subjects

- a focus on developing higher level cognitive skills rather than factual recall

- task presentation that generates intrinsic rather than extrinsic motivation

In this interactionist view children are seen as explorers of meaning, as critical and creative thinkers who have contributions to make both in the classroom and in the world beyond. Rather than regarding children only as consumers of predetermined knowledge, the emphasis in language teaching is on enriching the child through literature and on helping the child become a creator of literature. This interactionist view of children's learning is consistent with Piaget's theory which stresses action on the environment as crucial for the development of cognitive operations and with Vygotsky's theory which emphasizes social interaction as the matrix within which higher level thought processes develop. ${ }^{2}$

Clearly, very different applications of microcomputers are likely to result from each of these two pedagogical models. The transmission model is likely to give rise to more efficient procedures of task presentation and sequencing that can be individualized according to children's current level of knowledge of the subject matter. The emphasis is on the computer as tutor (Taylor, 1980). The reciprocal interaction model, on the other hand, will emphasize the computer as a tool that can enhance a variety of active learning activities, but particularly written communication. In order to understand the potential role of the microcomputer in promoting creative writing and cultural interchange, it is necessary to consider recent developments in our understanding of how writing is 
acquired and how it can best be encouraged in the classroom.

\title{
RECENT DEVELOPMENTS IN THE TEACHING OF WRITING
}

The extent to which writing activities had declined in North American schools was forcefully brought home to educators with the publication of Donald Graves' (1978) study entitled "Balance the Basics. Let Them Write." Graves documented the fact that writing received minimal attention in comparison to reading and most of the writing that students did carry out was copying. Feedback that students received on their writing tended to focus on the correctness of surface forms (e.g. grammar and spelling). This preoccupation with correctness of surface forms persisted despite considerable evidence that correction of students' writing errors and explicit teaching of grammar were not particularly effective. For example, Elley (1981) summarizes the findings of his extensive longitudinal study on teaching of grammar as follows:

\begin{abstract}
Pupils who had no formal grammar lessons for three years were writing just as clearly, fluently and correctly as those who had studied much grammar, the only apparent difference being that the pupils who hadn't studied grammar enjoyed English more... The research evidence overwhelmingly shows that increasing the amount of analytic study of language has no positive effect on pupils' ability to read or write. $(1981$, p. 12)
\end{abstract}

Many teachers operating from within a transmission model have difficulty in accepting that "errors" in grammar or spelling should not necessarily be immediately corrected, despite the evidence from both first and second language acquisition that explicit error correction is ineffective. The analogy with spoken language acquisition helps to explain the function of developmental "errors" in the acquisition of written competence. In drawing this analogy, Temple et al. (1982), for example, point out that the two processes are similar in that children normally take a great deal of initiative in learning both to talk and to write and for both processes to occur, children must be surrounded by language used in meaningful ways. They go on to note that

Children learn to talk by formulating tentative rules about the way language works, trying them out, and gradually revising them. At first, they make many mistakes in speech, but they gradually correct them. In writing we see errors of letter formation, spelling, and composition occurring as children make hypotheses about the rules that govern the writing system; errors give way to other errors before they arrive at correct forms. (1982, p. 9) 
In other words, if children are exposed to a wide variety of written language and if they are allowed to continue to express themselves in writing, then errors will gradually approximate adult usage without explicit correction.

Correction, in fact, can have negative consequences for writing development in much the same way as for spoken language acquisition. As expressed by Smith (1983):

Children do not learn from being corrected but from wanting to do things the right way. Most of the immense labor teachers put into correcting their students' work is wasted; it is ignored. If it is not ignored, then it may have a negative effect, with children avoiding the words they fear they cannot spell or pronounce correctly. They do not become better spellers or speakers by writing or talking less. Correction is useful, and it is only paid serious attention to, when the student wants it and would indeed be offended if it were not given. (1983, p. 138)

In conclusion, children acquire writing skills by engaging in writing activities that are creative and intrinsically interesting. Formal skills are gradually acquired in the context both of continued reading (Smith, 1982) and of projects to which children are actively committed. As Smith points out, children do not want "spelling mistakes in the poster they put on the wall, the story they are circulating, or the letter they will mail" (1983, p. 138). Rather than attempting to control this process, the teacher's roles include being a guide, facilitator, and most important, communication partner. Essentially, teachers organize the classroom in such a way that children's active involvement is maximized in projects to which the children themselves are committed.

Graves' (1983) work has begun to bring about a major change in the way writing is taught in North American schools. The change is essentially one from a transmission to a reciprocal interaction model of pedagogy. The "process" approach which Graves has advocated emphasizes writing as a meaningful communicative activity in which there is a real purpose (e.g. publication of a book within the classroom), a genuine audience (e.g. peers, teachers, parents), and support systems to assist children work through the editing of successive drafts. As expressed by Sanaoui (1985), these support systems require particular kinds of classroom organization:

As students are working on several consecutive drafts, they take part in various group activities. For example, groups of children discuss their choice of topics and talk about the ideas which will be included in their pieces of writing. Others read their stories to critical listeners whose role is to make suggestions for improve- 
ment. A third group acts as an editorial committee for the publication of works produced by the class. Briefly, the writing class becomes a writers' workshop. $(1985$, p. 1)

Although innovative within the North American context, these same ideas had been implemented by Celestin Freinet in France as early as the 1920's. Freinet's work resulted in a network of correspondence between schools in various regions of the country. Five thousand school newspapers and newsletters were published regularly, two of which, La Gerbe and Art Enfantin, became increasingly popular in several European countries.

A project implemented in the National Heritage Language Resource Unit (NHLRU) has recently applied these ideas to writing instruction for minority students within heritage language classes (Cummins, et al., 1986). ${ }^{3}$ It was found that students' interest and motivation in writing increased significantly, and the status of the heritage language within the schools increased substantially as a result of the perception of regular teachers that educationally worthwhile activities were being conducted in the heritage language class. Writing folders in Italian, Portuguese, and Spanish were developed in the context of the project in order to help students organize their writing.

The results of this project suggested that the experience of creative writing is particularly significant in developing a sense of academic efficacy among minority students. Daiute (1985) has expressed the potential of interactionist approaches to writing in promoting this sense of efficacy:

Children who learn early that writing is not simply an exercise gain a sense of power that gives them confidence to write-and write a lot... Beginning writers who are confident that they have something to say or that they can find out what they need to know can even overcome some limits of training or development. Writers who don't feel that what they say matters have an additional burden that no skills training can help them overcome. (p. 5-6)

Traditional approaches to writing that emphasize correctness of surface forms are particularly destructive for minority students whose knowledge of the school language in the early grades is frequently limited.

This section has outlined an approach to the teaching of writing that derives from principles of a reciprocal interaction model of pedagogy. The microcomputer is clearly not an essential part of this approach. However, the computer has tremendous potential to enhance this process by increasing the audience for students' writing and by facilitating the editing and production process. The research evidence also indicates that, in addition to providing possibilities for international communication, microcomputers can increase the immediate social interaction within the classroom. 


\section{THE MICROCOMPUTER AS A TOOL FOR SOCIAL INTERACTION AND CULTURAL EXCHANGE}

A number of investigators have stressed that the computer encourages a positive form of social interaction and collaboration among students. Canale, et al. (1984), for example, conclude

What stands out in all these cases is the social nature of computer use. Perhaps it is one of the virtues of necessity, but the scarcity of hardware brings with it what all teachers we have observed generally agree is a positive benefit-authentic interaction among the students as they negotiate both for access to the machines and while using them. (p. 7)

Mehan, et al. (1984) have similarly stressed that "while the microcomputer itself cannot transform unskilled writers into skilled ones, it does present a medium that makes a new social organization for reading and writing possible (p. 516). They attribute the positive effects they observed on students' writing to this social organization:

The presence of this 'other' during the writing process helps students generate ideas and give immediate responses to the written text. Students frequently challenge one another's sentences as 'not making any sense' or correct the spelling of a word as it was typed. Less frequently, but more important for the writing process, students discuss whether two sentences should be conjoined, how run-on sentences should be divided, or how to substitute for overused words. (p. 517-8)

A similar conclusion emerges from an ethnomethodological study of collaboration in word processing carried out in Toronto (Heap, 1985):

The social mediation of composition and inputting make collaborative writing something more, and different, than solo writing.... This research...has come to understand the social organization of collaboration as having value for intertwining and developing all the language arts. While writing is the task, the methods include speaking, listening and reading. (1985, p. 59)

One of the few studies carried out with minority language children (at the grade 1 level) also reaches a similar conclusion:

This project demonstrates that the computer can be used to develop literacy among very young children regardless of their initial ability to read or write. The creative process was reinforced by having the adults act as facilitators helping the students solve the problem of writing what they want, rather than dictating what 
should be written. The children became peer tutors helping each other, increasing their appreciation for language and appropriate expression. (Brisk, 1985, p. 31)

It appears clear from these studies that the microcomputer has the potential to reorient instruction from transmission towards interactional classroom structures. From the perspective of language learning theory, the presence of both immediate and distant audiences is especially significant in students' use of computers for writing. Swain and Wong Fillmore (1984) recently proposed a synthesis of the views of leading second language acquisition researchers whom they interviewed in the form of an "interactionist theory" whose major proposition is that "interaction between learner and target language users is the major causal variable in second language acquisition" (p. 18).

The potential of microcomputers to provide immediate and direct access to an international audience clearly has significant implications for language and literacy development as well as for cultural exchange and reinforcement. The technology exists to send written documents around the world in a matter of seconds and even to have written "conversations" with individuals in distant countries.

A significant innovation in recent years has been the institution of computer writing networks through which classes of students create newsletters, books, and other forms of information exchange that can be shared with other classes tied into the same network. The most notable example of this is the Computer Chronicles Newswire which operates out of San Diego on the west coast of the United States. The potential of this type of system to transform traditional approaches to teaching literacy skills is vividly illustrated in the following account of the system in operation taken from the Connecticut Bilingual Education Reporter, vol. 2, no. 1, Fall 1985: "Imagine, then, a bilingual classroom that has become a bilingual
newsroom...

The newsroom is busy today. You hear a lot of talking going on, but it's the kind of low, friendly buzz you would expect from the children-or rather, from the REPORTERS - whenever there's a press deadline coming up. You notice three kinds of activity: reporting, editing and production...

\section{REPORTING}

Actually, all of the reporters aren't even in the newsroom. In one corner of the room is the teletype that is hooked up to an international wireservice called, let's say, BPI (Bilingual Press International). You see, this paper prints stories from its foreign correspondents, who work for news organizations in Australia, 
Israel, Japan, Mexico, Puerto Rico and Spain.

Then there are the national reporters in Alaska, California, Hawaii and Pennsylvania. Not to mention the state correspondents in Bridgeport, Hartford and New Haven. All these stories come over the newswire. And the reporters in this newsroom send their best stories to be printed in newspapers around the state, the nation and the world.

Of course, the heart of any newspaper are local reporters, the ones you see when you walk into this bilingual classroom...oops! I mean, bilingual NEWSroom. Some are going over the notes they made during interviews, another is "clacking" away at the word processor, still others are proofreading their copy. A few are translating articles with the staff linguist (the teacher). All in preparation for...

\section{EDITING}

All stories - whether local, state, national or international-must pass muster with the editorial board. Lots of news comes over the newswire, and the editors have to read all of it - but they can't print it all!

Every local reporter knows that she or he might have to re-write their story several times before it has that special "punch" that will grab the reader's attention. So, several times a week the reporters sit around in a circle and read their stories to each other, both offering and receiving advice from their colleagues.

The suggestions range from how to make an article more interesting all the way down to spelling and punctuation. It's funny, but a newsroom is different from most classrooms. Everyone cares more about the CONTENT of the article in the first drafts - typos can wait till the final draft. But ALL errors are corrected before...

\section{PRODUCTION}

Artwork, layout, typesetting, paste-up. Some of the work is computerized, but much is done just as it was 200 years ago. And the end-product hasn't really changed at all.

These reporters feel proud when they finally read their work IN PRINT. They know that hundreds will read what they've written. But they also feel part of something larger. After all, they are writing for a local newspaper AND an international wireservice. They have joined the club of world-class writers...

\section{THE NHLRU INTERNATIONAL COMPUTER WRITING NETWORK PROJECT}

Building upon the intitiative and experience of the Computer Chronicles Newswire, the NHLRU is in the process of implementing a multilingual 
student writing network which will link Canadian students with their peers in other countries for purposes of language and literacy development as well as cultural exchange and reinforcement. A grant of multilingual text processing equipment (The Xerox Star system) as part of a joint project with the Department of East Asian Studies of the University of Toronto has provided the basis for establishing an international network. The Star system can be directly linked to IBM-compatible microcomputers in classrooms. Other microcomputer models can access the proposed international network system through mainframe computers to which the Star can be linked.

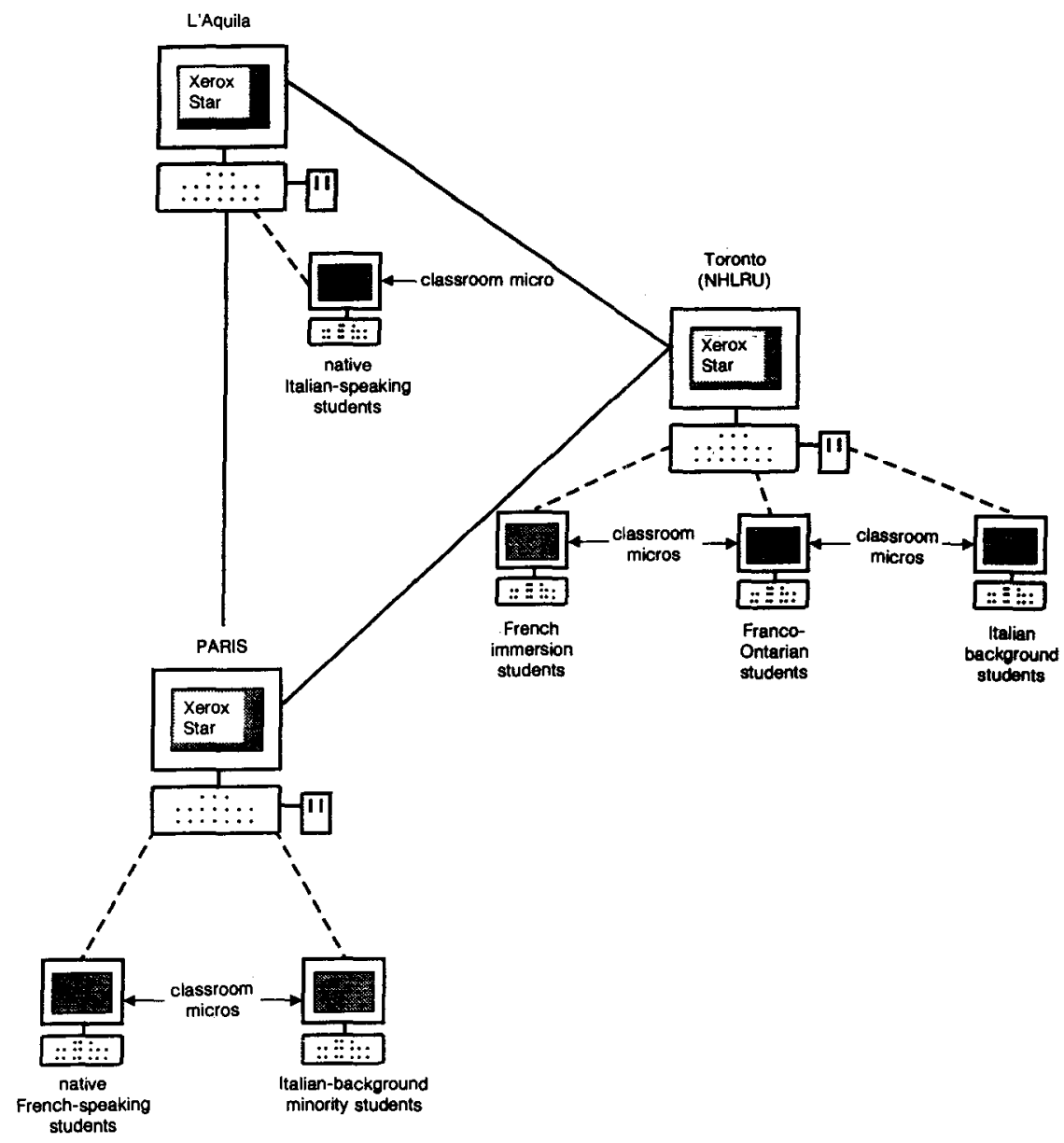

Figure 1: Illustration of Possible Computer Writing Network between Paris, L'Aquila and Toronto 
A schematized version of how an international network involving the Xerox Star system might operate for schools in Paris, L'Aquila and Toronto is illustrated in Figure 1.

Three groups of grade 6 students in Toronto are involved in the scheme illustrated in Figure 2: French immersion students (i.e. students from English-home backgrounds instructed largely through French in the early grades as a means of developing fluent bilingual skills), Franco-Ontarian students (i.e. those from minority French-speaking backgrounds in largely French language schools), and Italian-background students instructed mainly through English but with about two-and-one-half hours instruction in both Italian and French per week. Both French immersion and Franco-Ontarian students communicate in French with native French-speaking students in Paris. Depending upon the abilities and interests of the particular classes involved, the writing link might be in just one language or in two languages. For example, the immersion and minority Francophone classes might write in French and their twin classes write back in English. The immersion and Francophone classes in Toronto clearly can also exchange writing. The Italian-background students in Toronto are linked with native Italian-speakers in L'Aquila and with minority Italian students in Paris. There is also a link between the L'Aquila and Paris Italian students. Again, a variety of possibilities exist for language sharing and exchange.

The basic procedure envisaged is that final versions of students' writing will be entered on microcomputer and sent by modem to a local Star system (perhaps in Languages or Computer Science Departments of universities). These can then be quickly and relatively inexpensively transmitted between the Star systems in the different cities and subsequently accessed by the classes in each city and printed out on classroom microcomputers. Obviously, a large number of variations and elaborations to this basic procedure are possible; for example, micro-to-micro communication without going through a central computer is feasible for relatively small local networks. An elaboration of the communication network would be for students in each site to create videos on aspects of their lives and cultures for exchange with students in other sites.

\section{OBJECTIVES OF THE NETWORK}

The specific objectives of the project will vary according to the particular groups involved. However, some central objectives are likely to be 
common to many situations. These are outlined and briefly discussed below:

\section{Language Learning/Maintenance}

There is some-degree of consensus among applied linguists that the most important factor determining language learning is sufficient communicative interaction with speakers of (or text in) the target language. The computer writing network is capable of supplying the meaningful interaction that second language classrooms often lack. It is also capable of encouraging minority students to continue to develop literacy skills in their mother tongue.

\section{Literacy Development}

The effectiveness of "process" approaches to writing, popularized by Graves (and before him, Freinet), in which students actively generate their own creative writing and publish it for real audiences is seldom questioned. However, it requires a change of orientation among teachers from a "transmission" to a "reciprocal interaction" mode of teaching. In other words, teachers must be prepared to acknowledge that active student use of language (both talking and writing) are important means to learning. Many teachers (in both regular and second language classrooms) find it difficult to reorient their teaching from an emphasis on transmission of knowledge and skills to one where the generation and exploration of ideas through dialogue and interaction are encouraged. The incentive provided by international communication is likely to encourage a greater number of teachers to redefine their teaching roles and allow students more opportunities to develop their literacy skills through writing. Clearly, the reading and editing for publication of other students' writing from around the world will also contribute to literacy skills development.

\section{Cultural Exchange and Reinforcement}

In an era where our images of other cultures and nations are considerably influenced by television-reinforced stereotypes, the educational relevance of establishing a system for genuine communication and real cultural exchange is obvious. Within Canada, for example, few would dispute the desirability of greater possibilities for interchange between French-speaking students in Quebec and English-speaking (or Frenchspeaking) students in other parts of Canada. A significant increase in cross-cultural understanding and sensitivity is likely to result from a writing exchange made possible by the computer network. For minority students who are often ambivalent about their cultural identity, the net- 
work opens up additional possibilities. For example, Italian-speaking students in Toronto or Paris who are communicating with their peers in Italy are reinforcing their sense of Italian-Canadian (or Italian-French) cultural identity. For minority students who return to their country of origin (an increasing trend in Europe) a computer writing link-up with their country of immigration can help them maintain linguistic and cultural contacts. For example, Italian students who return to Italy after growing up in Germany could continue to develop their German skills and knowledge of German culture by means of a writing connection with Germany.

\section{Artistic Expression}

Newer generations of computer programs permit easy integration of text and graphics. It is thus possible for students to illustrate their stories on the computer and transmit the illustrations as well as the text (see Piestrup, 1982).

\section{Computer Literacy}

As children use the computer and see its possibilities they are likely to want to explore other applications of computers to their lives. Among older students, programming applications will be encouraged and, once again, international exchange of programs is likely to provide considerable incentive.

\section{International Educational Cooperation}

The computer connections established between classes of students will also allow their teachers to communicate with each other and will encourage cross-national contact and cooperation in a variety of other educational areas. For example, student exchanges where students spend periods of time in other countries are likely to be encouraged by the writing connection. The impact of such exchanges is likely to increase if followed or preceded by a computer writing exchange.

\section{Potential Scope and Applications of the Project}

In order to communicate the potential scope of the international computer writing network, we have outlined potential "user groups" or "target groups" within Canada and have tried to specify linguistic and cultural issues faced by these groups that can potentially be addressed by the writing network. A similar variety of target groups could be specified for virtually any country. Because we see the creation of videotapes by students as an activity that will naturally evolve from and enhance the 
cross-cultural writing contact, we have included that activity in the chart (Figure 2).

\begin{tabular}{|c|c|c|c|}
\hline Canadian Target Group & Specific Problems/Issues & $\begin{array}{l}\text { Writing/Video } \\
\text { Contact Group } \\
\text { (Canada) }\end{array}$ & $\begin{array}{c}\text { Writing/Video } \\
\text { Contact } \\
\text { Group (International) }\end{array}$ \\
\hline $\begin{array}{l}\text { 1. Regular classroom } \\
\text { students }\end{array}$ & $\begin{array}{l}\text { - Writing development } \\
\text { - Knowledge of other } \\
\text { cultures }\end{array}$ & $\begin{array}{l}\text { Any class in Canada (writing in } \\
\text { English/French) }\end{array}$ & $\begin{array}{l}\text { Any class capable of writing in } \\
\text { English/French }\end{array}$ \\
\hline 2. French immersion students & $\begin{array}{l}\text {-inadequate expressive } \\
\text { French skills in oral and } \\
\text { written modes (usually } \\
\text { attributed to lack of } \\
\text { genuine interaction } \\
\text { possibilities) }\end{array}$ & $\begin{array}{l}\text { - Native French-speaking } \\
\text { students } \\
\text {-Other immersion students }\end{array}$ & $\begin{array}{l}\text { French-speaking students in } \\
\text { Europe or Caribbean }\end{array}$ \\
\hline $\begin{array}{l}\text { 3. Minority francophone } \\
\text { students }\end{array}$ & $\begin{array}{l}\text { - Need for reinforcement of } \\
\text { French and English written } \\
\text { skills } \\
\text { - Cultural identity issues }\end{array}$ & Quebec francophone students & $\begin{array}{l}\text { French-speaking students in } \\
\text { Europe or Caribbean }\end{array}$ \\
\hline $\begin{array}{l}\text { 4. Heritage language } \\
\text { learners } \\
\text { (Groups specifically } \\
\text { identified to date: } \\
\text { Portuguese, Spanish, } \\
\text { Italian, Greek, Chinese, } \\
\text { Japanese, Armenian) }\end{array}$ & $\begin{array}{l}\text { - Need for heritage language } \\
\text { literacy skills reinforcement } \\
\text { - Cultural identity issues }\end{array}$ & $\begin{array}{l}\text { Learners of the same language } \\
\text { in various types of Canadian } \\
\text { programs }\end{array}$ & $\begin{array}{l}\text { - Native-speakers in the } \\
\text { country of origin } \\
\text { - Minority students from the } \\
\text { same background in other } \\
\text { countries } \\
\text { - Non-minority students } \\
\text { learning the heritage } \\
\text { language (e.g. in immersion } \\
\text { programs such as those of } \\
\text { the Edmonton Board) }\end{array}$ \\
\hline $\begin{array}{l}\text { 5. Minority dialect or creole- } \\
\text { speaking students (e.g. } \\
\text { from Caribbean) possibly } \\
\text { in "Black Cultural } \\
\text { Heritage" programs } \\
\text { (Ontario) }\end{array}$ & $\begin{array}{l}\text { - Low academic achievement } \\
\text {-Cultural identity issues }\end{array}$ & $\begin{array}{l}\text { Students from the same region } \\
\text { or country of origin across } \\
\text { Canada }\end{array}$ & $\begin{array}{l}\text { - Any class capable of writing } \\
\text { in English/French } \\
\text { - Students from the } \\
\text { region/country of origin }\end{array}$ \\
\hline 6. Inuit and Indian students & $\begin{array}{l}\text { - Low academic achievement } \\
\text { - Cultural identity issues } \\
\text { - Need for aboriginal } \\
\text { language reinforcement }\end{array}$ & $\begin{array}{l}\text { - Similar language groups } \\
\text { across Canada (writing in } \\
\text { aboriginal language) } \\
\text { - Any class in Canada (writing } \\
\text { in English/French }\end{array}$ & $\begin{array}{l}\text { - Aboriginal peoples in other } \\
\text { countries } \\
\text { - Any class capable of writing } \\
\text { in English/French }\end{array}$ \\
\hline 7. ESL/EFL & $\begin{array}{l}\text { - Need for English language } \\
\text { reinforcement }\end{array}$ & $\begin{array}{l}\text { - Other ESL/EFL classes } \\
\text { - Regular classes }\end{array}$ & $\begin{array}{l}\text { - Any class capable of writing } \\
\text { in English/French }\end{array}$ \\
\hline $\begin{array}{l}\text { 8. Language learners at } \\
\text { university level }\end{array}$ & $\begin{array}{l}\text { - Need for target language } \\
\text { reinforcement }\end{array}$ & $\begin{array}{l}\text { - Other university learners of } \\
\text { target language }\end{array}$ & $\begin{array}{l}\text { - Native speakers of target } \\
\text { language (preferably } \\
\text { learners of English/French so } \\
\text { that language exchange } \\
\text { becomes possible) }\end{array}$ \\
\hline
\end{tabular}

Figure 2: Potential Scope of the International Student Network: Canadian Target Groups and Issues that can be Addressed 


\section{CONCLUSION}

Currently in North American many educators are confused about appropriate ways of using computers in schools. Schools have invested heavily in purchasing microcomputers but, in many cases, they lie unused because teachers have received little training in how to use computers and how to evaluate educational software. I have suggested in this paper that this confusion exists, at least in part, because educators have failed to resolve more fundamental pedagogical issues. Decisions about appropriate uses of computers are dependent upon prior clarification of general educational philosophy. All software incorporates explicit or implicit assumptions about how children learn and about appropriate ways of teaching children.

Two broad sets of assumptions can be identified with respect to the use of computers for promoting language and literacy development. These assumptions or pedagogical models reflect what has been termed "transmission" and "reciprocal interaction" models of teaching. The transmission model is based largely on behaviouristic psychology and views the the computer as a "tutor" which takes over the role of the teacher to transmit information, knowledge or skills. The knowledge and skills are preprogrammed and the student's role is to receive this knowledge. The interactional pedagogical model views the computer as a tool for students to use to achieve some goal that they are motivated to achieve. The student is generating knowledge rather than receiving it and the computer can provide guidance, facilitation and support to help students achieve their goals.

At the present time, research suggests that most pedagogical applications of microcomputers reflect transmission rather than interactional assumptions. If this trend continues, I predict that microcomputers will have minimal impact on our educational systems, amounting to little more than expensive textbooks or workbooks that continue to confine students to passive roles within the classroom. However, I believe that these trends will change, largely as a result of the power of microcomputers to enhance central ingredients for the development of students' literacy skills (such as audience, ease of editing, publication and sharing processes, etc.).

In other words, the progression I envisage is one whereby innovative projects such as the Computer Chronicles Newswire and the NHLRU International Writing Network, will demonstrate the potential of an interactionist pedagogical model to enhance students' literacy skills; other educators will be led to explore and adopt this model in order to exploit the power of computers in their own classrooms. Thus, the computer has the potential to act as a catalyst for fundamental changes in the way 
schools are organized and knowledge is transmitted. Ironically, these "fundamental changes" simply reflect what cognitive psychologists such as Piaget and Vygotsky have emphasized about children's learning for more than half a century. Learning is viewed as an active process that is enhanced through interaction. This stress on action (Piaget) and interaction (Vygotsky) contrasts with behaviouristic pedagogical models that focus on passive and isolated reception of knowledge. Classroom microcomputers can be used within either of these pedagogical frameworks; however, their potential within an interactionist framework is so much greater than within a transmission (behaviouristic) framework that their increasing use in schools is likely to bring about a gradual change towards pedagogical models that liberate students from dependence on instruction. In short, rather than controlling and restricting students' access to knowledge, microcomputers have the power to broaden students' experiential base by facilitating intercultural contact and collaboration in the generation of knowledge.

\section{FOOTNOTES}

1 Based on a paper presented at the Symposium on Italian and Canadian Educational Systems, Istituto Regionale di Ricerca Sperimentale ed Aggiornamento Educativi D'Abruzzo, L'Aquila, Italy, November 1985.

2 It is interesting to note that these assumptions characterize the education of "gifted" children in most North American schools. "Gifted" students are seen as active, inquiring, involved individuals who thrive on self-directed problem-solving and learning which is not provided in regular classrooms. The implicit assumptions underlying such programs are that "non-gifted" students are much less capable of active inquiry and would not benefit from the opportunity to become actively involved in adopting and pursuing their own learning goals; therefore, regular curricula should not (and hence, do not) foster active involvement by students in independent learning. These implicit assumptions are closely associated with transmission approaches to teaching and are likely to become self-fulfilling.

${ }^{3}$ These classes are funded by the provincial government in Ontario and provide two-andone-half hours of instruction per week outside of regular school hours in languages other than English or French.

\section{REFERENCES}

Barnes, D. (1976). From communication to curriculum. Harmondsworth: Penguin.

Becker, H.J. (1982). Microcomputers in the classroom: Dreams and realities. Baltimore, MD: CSOS, The Johns Hopkins University, Report no. 319.

Brisk, M.E. (1985). Using the computer to develop literacy. Equity and Choice, $1,25-32$. 
Canale, M., Barker, G., Belanger, M., MacRuary, K., McLean, R.S., \& Ragsdale, R.G. (1984). Microcomputer software for language arts in Ontario: Survey and analysis. Final report of OISE project 82-3916.

Chomsky, C. (1981). Write now, read later. In C. Cazden (Ed.), Language in Early Childhood Education. 2nd Edition. Washington, D.C.: National Association for the Education of Young Children.

Cummins, J. (1984). Bilingualism and special education: Issues in assessment and pedagogy. Clevedon, England: Multilingual Matters. Co-published in the United States by College-Hill Press, San Diego.

Cummins, J., Aguiar, M., Bascunan, L., Fiorucci, S., Sanaoui, R., \& Basman, S. (1986). Literacy development in heritage language programs. Toronto: National Heritage Language Resource Unit.

Daiute, C. (1985). Writing and computers. Reading, Mass.: Addison-Wesley. Elley, W.B. (1981). Why teach a centipede to walk? Education (New Zealand), 3, 11-13.

Giacobbe, M.E. (1982). Who says children can't write the first week? In R.D. Walshe (Ed.), Donald Graves in Australia: "Children want to write." Exeter, New Hampshire: Heinemann Educational Books Inc.

Goodman, K.S. \& Goodman, Y.M. (1977). Learning about psycholinguistic processes by analysing oral reading. Harvard Educational Review, 47, 317333.

Graves, D. (1983). Writing: Children and teachers at work. Exeter, NH: Heinemann.

Heap, J.L. (1985). Collaboration in word processing: The impact of technology on education: The evolving role of the student. Final report presented to the Ministry of Education, Ontario.

HMSO, (1975). A language for life. Report of the Committee of Inquiry appointed by the Secretary of State for Education and Science under the chairmanship of Sir Alan Bullock. London.

Holdaway, D. (1979). Foundations of literacy. New York: Ashton Scholastic.

Lindfors, J.W. (1980). Children's language and learning. Englewood Cliffs, New Jersey: Prentice Hall.

Mehan, H., Miller-Souviney, B., \& Riel, M.M. (1984). Knowledge of text editing and the development of literacy skills. Language Arts, 65, 154-159.

Piaget, J. (revised 1960). Language and thought of the child. London: Routledge \& Kegan-Paul.

Piestrup, A.M. (1982). Young children use computer graphics. Harvard Computer Graphics Week, Harvard University Graduate School of Design. (ED 224564).

Plata, M. (1982). Assessment, placement, and programming of bilingual exceptional pupils: A practical approach. Reston, Virginia: The Council for Exceptional Children.

Sanaoui, R. (1985). Learning how to write in the heritage language. Manuscript adapted from “L'apprentissage de l'expression écrite dans les langues d'origine." Heritage Language Bulletin, 1, 6-7.

Smith, F. (1978). Understanding reading. 2nd edition. New York: Holt, Rinehart \& Winston. 
Smith, F. (1982). Writing and the writer. New York: Holt, Rinehart \& Winston. Smith, F. (1983). Afterthoughts. In F. Smith, Essays into literacy. Exeter, New Hampshire: Heinemann Educational Books, Inc.

Swain, M. \& Wong Fillmore, L. (1984). Child second language development: Views from the field on theory and research. Paper presented at the 18th Annual TESOL Conference, Houston, Texas, March.

Taylor, R. (1980). The computer in the school: Tutor, tool, tutee. New York: Teachers' College Press.

Temple, C.A., Nathan, R.G. \& Burris, N.A. (1982). The beginnings of writing. Boston: Allyn \& Bacon.

Vygotsky, L. (1962). Thought and language. Cambridge, Mass.: MIT Press.

Wells, G. (1982). Language, learning, and education. Bristol, England: Centre for the Study of Language and Communication, University of Bristol.

\section{THE AUTHOR}

Jim Cummins was born in Dublin, Ireland. He carried out his doctoral research in Canada on the consequences of bilingualism for children's cognitive development and obtained his Ph.D. from the University of Alberta in 1974. His research interests include language planning and public policy issues related to bilingualism and bilingual education, patterns of language acquisition and academic development among minority students, and the effects of teaching practices on the development of language and literacy. He currently directs the National Heritage Language Resource Unit within the Modern Language Centre of the Ontario Institute for Studies in Education. 
